\title{
Comparison of the Mindfulness Skills, Metacognitive Beliefs and Perceived Stress in Hypertension Patients and Control Group
}

\author{
Zohreh Haji-Mirsaeidi ${ }^{1}$, Hamid Kazemi-Zahrani ${ }^{2}$ \& Masoumeh Sadeghi ${ }^{3}$ \\ ${ }^{1}$ Department of Psychology, Najafabad Branch, Islamic Azad University, Najafabad, Isfahan, Iran \\ ${ }^{2}$ Department of Psychology, Payame Noor University, Tehran, Iran \\ ${ }^{3}$ Cardiac Rehabilitation Research Center, Cardiovascular Research Institute, Isfahan University of Medical \\ Sciences, Isfahan, Iran \\ Correspondence: Hamid Kazemi-Zahrani, Department of Psychology, Payame Noor University, PO BOX: \\ 19395-3697, Tehran, Iran. E-mail: kazemi@nj.isfpnu.ac.ir
}

Received: March 9, 2016 Accepted: April 26, 2016 Online Published: May 18, 2016

doi:10.5539/gjhs.v9n1p138 URL: http://dx.doi.org/10.5539/gjhs.v9n1p138

\begin{abstract}
The aim of this study was to compare the skills of mindfulness, metacognitive beliefs and perceived stress in hypertension patients and control group. The study was a causal-comparative one. The population included all patients with high blood pressure who were admitted in Isfahan Cardiovascular Research Institute in 2014, 90 of which were selected by purposive sampling. Research instruments include: Kentucky's mindfulness skills (Baer, Smith, \& Allen, 2004), metacognitive beliefs questionnaire (Welles, 1997) and questionnaire perceived stress (Cohen \& Kamarck, 1983). Of all the questionnaires returned, 80 were fully completed and therefore analyzed. Data were analyzed using a t-test and multivariate analysis of variance. Results showed that there is a difference between mindfulness skills and beliefs of people with hypertension and control group. Moreover, the results showed that there isn't any meaningful difference between the perceived stress in patients with hypertension and control group. It can be said that mindfulness skills, metacognitive beliefs and perceived stress can help us to understand the psychological issues of patients with high blood pressure better.
\end{abstract}

Keywords: mindfulness skills, metacognitive beliefs, perceived stress, hypertension

\section{Research Background}

Physiological psychology disorders are those physical disorders which are thought to be under the great effects of psychological issues. Up to now the researches on physiology psychology were often limited to the diseases such as asthma, hypertension peptic ulcers, inflammatory bowel disease and rheumatic joint pain (Cartwright \& Panchal, 2011). Hypertension is a widespread disease which has no symptoms (silent killer). It is the pressure exerted on the vessels by the flowing blood in them and its values is determined via two measures: one for the volume-expanded hypertension (diastolic), and another for systolic hypertension. The systolic measure is the value of venous pressure when ventricles are contracted and the heart is pumping. The diastolic measure shows the degree of venous pressure when ventricles and heart are at rest. Normal systolic hypertension is lower than $120 \mathrm{mmHg}$, while normal diastolic hypertension is lower than $90 \mathrm{mmHG}$. However, if diastolic hypertension is higher than $90 \mathrm{mmHg}$, or systolic hypertension is equal to or higher than $130 \mathrm{mmHG}$, we are facing systemic hypertension (Dimattw, 2004).

Primary blood pressure is a pressure with no physical symptom and is usually caused by physiological and psychological factors (Ely \& Mustard, 2005). Experts believe that psychological factors such as the way of encountering stress, self-confidence, oppressed anger, characteristic typology and individuals' beliefs are very important in development and exacerbation of hypertension (Dressler, Estentus, \& Vitroy, 2013). This disease has some complications such as heart failure, brain stroke and kidney failure (Anderson, 2008). Therefore, hypertension is one of the most common and important health threats and almost one eighth of general deaths number is because of high blood pressure or its complications (Robi, 2011). Physiological psychology area's researchers have been more concerned with finding the relationship between any particular disease and person's attitude or methods used when encountering tension arousing events and mental pressure (Cartwright \& Panchal, 2011). In this context, psychological stress model (Lazarus, 1999), beliefs, thoughts and recognition processes 
are introduced as mediator variables. Based on this model, individuals first assess the situation through mental processes, then the negative feeling will be activated if the situation is threatening or challenging. Therefore emotion precedes cognition (Roseman \& Smith, 2001). Although the model of tension arousing - affection factors proposed by Fox and Spector (2006) assumes the precedence of cognition to emotion but it expresses that the kind of emotional reactions which appear after assessment will be followed by negative or positive behaviors. In this model not only control is considered as a cognitive variable but also it watches the affection. Cognitive processing arouses excitements and feelings. If these processes are logical and compatible they will be followed by positive emotions and excitement, otherwise they will be followed by negative feelings and emotions (Bamber, 2012).

Although the above studies have mentioned the role of cognitive processes in arousing negative excitements and the related disorders, they have not mentioned anything about the role of mindfulness and metacognition. So the metacognitive approach argues that physiological psychology disorders are related to the activity of a useless model of metacognitive beliefs. False coping strategies are resulted from wrong beliefs and preserve concrete processing methods and maintain false beliefs (Luban, Hadduk, \& Ayndrmn, 2009). Inefficient interaction model of metacognitive knowledge and experience forms cognitive symptoms which according to Wells (2006) are the most-psychological structures associated with physiological psychology disorders. These syndromes cause a bias in automated processing of cognitive system lower level and will be accompanied by a wave of negative emotions including anger and neurotic (Wells \& Matthews, 2004). On the other hand, interactive cognitive infrastructure model designed by Teasdale (1993) to clearly elaborate the relationship between the cognition and affection emphasizes two types of cognition: "cold" and "hot". Hot cognition has a stronger relationship with affection (Teasdale, Segal, \& Williams, 2003). It seems that mind awareness not only is able to clarify the relationship between cognition and affection but also determine new aspects of body and mind link because of its cognitive structure, its flexibility and not being judicative (Shonin, Van Gordon, Slade, \& Griffiths, 2013). Britton, Shahar, Szepsenwol and Jacobs (2012) confirmed this argument by saying that if individual is in a pleasant mind awareness state won't have any chance to attract negative thoughts and attitudes because he is busy increasing capacity to accept thoughts and affections. Then he won't be inefficient anymore and his inefficient attitudes will decrease through excitement processing.

One of the other factors that affects high blood pressure by itself or in accompany with other factors is stress. The intensity of perceived stress is one of the main elements of health believe model (Sheeran \& Abraham, 2005). The intensity of perceived stress refers to a person's belief in the amount of stress seriousness. A person is likely to adopt specific coping strategies when he.she believes in the negative physical, psychological and social effects resulted from stress and its important consequences (for example, social relationships changes, independence decrease, pain and suffering, disability and even death) (Rosenstock, 2008). Related studies have shown that people whose perceived stress intensity is high or distorted, suffer from internal conflict and psychological impasse. They cannot handle their negative affections and will use avoidance and submission strategies in life-threatening situations. Therefore they are susceptible to high blood pressure (Fisher, 2012).

Previous studies acknowledge blood pressure as a result of perceived stress; however, they have not addressed the simultaneous presence of mindfulness and metacognition in patients suffering from distorted perceived stress. Considering the mentioned points patients with high blood pressure suffer from mental symptoms which are sometimes causing symptoms, sometimes aggravating factors and sometimes are the results of having high blood pressure. In this regard, due to inefficient beliefs and thoughts of these patients some effective psychological processes such as metacognitive beliefs and mindfulness can play an important role in the disease process. Also, given that stress is one of the most important factors in aggravation of the disease, a person's perception of these structures can also contribute to the acceptance and control of the disease.

Focusing on cognitive variables, the present research aims to study the difference between the control group and the group of patients with a combination of metacognitive beliefs, mindfulness skills and perceived stress who suffer from blood pressure. Therefore, the main question of the present study was: is there any meaningful difference between cognitive beliefs skills, mindfulness and perceived stress in people with high blood pressure and the control group members.

\section{Materials and Methods}

This research was a casual comparative post event research. This statistical model was chosen due to sampling limitations and research timing constraints. The population of the study included all patients with high blood pressure, which were admitted to Isfahan Cardiovascular Research Center in 2014. The reason for choosing this center as the only center for study was that it was the only accessible specialized center in Isfahan in which the 
researcher was able to do research.

The size of the sample was determined through Cochran formula. 100 patients were selected from the research population of 350 hypertension patients who referred to this center. The level of significance was $95 \%$ confidence. Twenty patients were eliminated at the end of the evaluation period, and 80 were finally analyzed by the study tools. The statistical population was patients of Isfahan from which one hundred were selected as the statistical sample. This sample size was calculated at the confidence level of $95 \%$ with $5 \%$ probability of error.

Based on purposive sampling, 100 patients diagnosed to have high blood pressure in Isfahan Cardiovascular Research Institute were chosen to participate in the study. The necessary criteria for the participants to be chosen were having the blood pressure higher than average after expert's diagnostic tests, filling consent form, being at the age range of 25 to 60 years, passing at least a fifth-grade education, not having diabetes, and exclusion criteria included having simultaneous acute psychiatric disorders, existence of a justifying biological basis for blood pressure problems and the reluctance of patients to participate in the study. Of all the gathered questionnaires, 20 half-completed ones were eliminated. The control group members were selected from among the relatives and family members of patients with similar characteristics and background (in terms of education, age, marital status and employment. The primary sample, consisting of one hundred people, showed a loss equal to 20 individuals.

\subsection{Instruments}

The research instruments used in this study are:

1) Kentucky Mindfulness Skills questionnaire: The 39-item questionnaire was designed by Baer, Smith and Allen (2004) to measure four Mindfulness elements: observership, description without Label, performance along with awareness and acceptance without judgment. The questions are answered based on the 5-point Likert scale. Baer et al. (2004) reported internal consistency (Alpha coefficient) of .76 to .91 for four subsidiary scales. Preliminary and final factor analysis supported the four factor structure and showed that they were related to many other variables. Studies showed that the scores of the scale had a low correlation with the scores resulted from patients suffering from borderline personality disorders.

2) Metacognition Beliefs questionnaire: The 30-item questionnaire designed by Wales (1997) has 5 components including positive beliefs related to cognitive confidence worries, cognitive self-awareness, negative beliefs related to uncontrollability of thoughts and beliefs and beliefs about controlling thoughts. Wales and Carter (1999) reported alpha coefficients credit of 0.72 to 0.87 and test-retest of .76 to .89 (quoted from Wells, 2006).

3) Perceived stress Questionnaire: This questionnaire is developed by Cohen and Kamark (1983) and assesses the amount of stress that the person has experienced during the last month. The scale is scored on five marks from never to very much (0-4). The test reliability was reported by internal consistency of alpha Chronbach 0.86 . Generally, the study's validity criteria are appropriate and not under the effect of gender and age (See Cohen \& Kamark, 1983).

Metacognitive beliefs defects $\rightarrow$ perceived stress $\rightarrow$ blood pressure disorder

Mindfulness skills $\rightarrow$ perceived stress $\rightarrow$ blood pressure disorder

\section{Results}

Participants of this study were aged from 29 to 67 . There were 30 men in experimental group and 33 in the control group. The prevalence of women in hypertension group was 50 and 47 women in control group. Table 1 shows the baseline variables of the two groups.

Multivariate ANOVA needs statistical provisions such as: 1) normality, 2) variance homogeneity 3) homogeneity of regression gradients and multiple linear, which were analyzed. Assumption of normality was examined by Kolmogrov-Smirnov test and was approved ( $p>0.05)$. Levine's test $(p>0.05)$ and Box $(p>0.05, F=1.70)$ also showed the equality of variance and covariance between the groups, therefore a multivariate analysis of variance can be used. The mean, standard deviation of mindfulness skills components' scores, cognitive beliefs and perceived stress in both groups of high blood pressure and control are presented in Table 2. 
Table 1. Descriptive measures - gender, occupation, and marital status - of the research sample for each group

\begin{tabular}{|c|c|c|c|c|c|c|c|}
\hline \multirow{2}{*}{\multicolumn{2}{|c|}{$\begin{array}{l}\text { Statistical indicators } \\
\text { Variable }\end{array}$}} & \multicolumn{2}{|l|}{ Patient } & \multicolumn{2}{|l|}{ Control } & \multicolumn{2}{|l|}{ Total } \\
\hline & & Frequency & Percent & Frequency & Percent & frequency & Percent \\
\hline \multirow{2}{*}{ Gender } & Male & 30 & 37.5 & 33 & 41.2 & 63 & 39.4 \\
\hline & Female & 50 & 62.5 & 47 & 58.8 & 97 & 60.6 \\
\hline \multirow{7}{*}{ Occupation } & Employee & 5 & 6.2 & 8 & 10.0 & 13 & 8.1 \\
\hline & Worker & 2 & 2.5 & -- & -- & 2 & 1.2 \\
\hline & Self-employed & 16 & 20.0 & 17 & 21.2 & 33 & 20.6 \\
\hline & Retired & 7 & 8.8 & 12 & 15.0 & 19 & 11.9 \\
\hline & Working after retirement & 3 & 3.8 & 5 & 6.2 & 8 & 5.0 \\
\hline & housekeeper & 45 & 56.2 & 37 & 46.2 & 82 & 51.2 \\
\hline & Unemployed & 2 & 2.5 & 1 & 1.2 & 3 & 1.9 \\
\hline \multirow{4}{*}{ Marital status } & Married & 60 & 75.0 & 64 & 80.0 & 124 & 77.5 \\
\hline & Single & 14 & 17.5 & 12 & 15.0 & 26 & 16.2 \\
\hline & Spouse passed away & 4 & 5.0 & 1 & 1.2 & 5 & 3.1 \\
\hline & Divorced & 2 & 2.5 & 3 & 3.8 & 5 & 3.1 \\
\hline
\end{tabular}

Table 2. Descriptive index of mindfulness skills, cognitive beliefs and perceived stress variables for every individual group

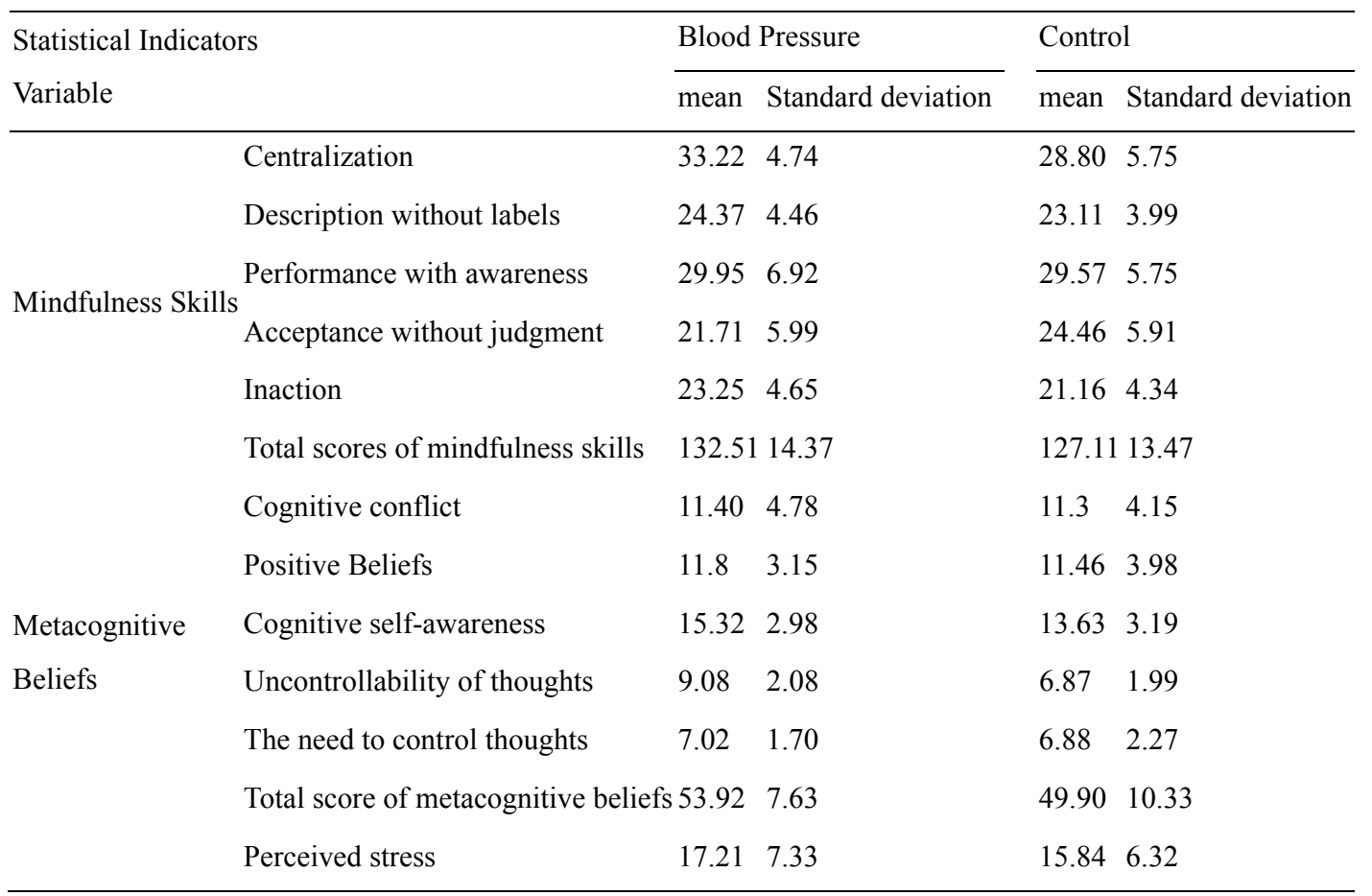

To investigate the effect of the group variable on mindfulness skills components, multivariate ANOVA was used. Multivariate analysis of variance for the components of mindfulness skills is presented in Table 3. 
Table 3. Results of multivariate analysis of variance for the components of mindfulness skills and beliefs

\begin{tabular}{|c|c|c|c|c|c|}
\hline Variable & Total squares & $\begin{array}{l}\text { Degrees } \\
\text { freedom }\end{array}$ & ${ }^{\text {of }}$ Mean square & $\mathrm{F}$ & $\begin{array}{l}\text { Significance } \\
\text { level }\end{array}$ \\
\hline Centralization & 783.22 & 1 & 783.22 & 18.19 & 0.001 \\
\hline Description without label & 63.75 & 1 & 63.75 & 3.55 & 0.06 \\
\hline Performance with awareness & 5.62 & 1 & 5.62 & 14.0 & 0.07 \\
\hline Acceptance without judgment & 302.50 & 1 & 302.50 & 8.53 & 0.004 \\
\hline Inaction & 174.30 & 1 & 174.30 & 8.42 & 0.004 \\
\hline Cognitive Conflict & 5.25 & 1 & 5.25 & 0.26 & 0.61 \\
\hline Beliefs Positive & 5.62 & 1 & 5.62 & 0.43 & 0.51 \\
\hline Cognitive self-awareness & 113.90 & 1 & 113.90 & 12.22 & 0.00 \\
\hline Uncontrollability of thoughts & 195.80 & 1 & 195.80 & 46.93 & $0 . .001$ \\
\hline Need To Control Thoughts & 0.75 & 1 & 0.75 & 0.18 & 0.66 \\
\hline
\end{tabular}

As Table 3 shows the results, there is a significant difference between the two groups in the case of observership, acceptance without judgment, inaction, cognitive self-consciousness and uncontrollability of thoughts, but there were no significant difference between the two groups in case of other components. To compare total scores of mindfulness skills, metacognitive beliefs and perceived stress in both high blood pressure and control groups, a t test was used results of which are presented in Table 4 . Table 4 shows the results of t-test to check the mindfulness skills, metacognitive beliefs and perceived stress between both groups of the research.

Table 4. Results of t-test to check the mindfulness skills, metacognitive beliefs and perceived stress between both groups of the research

\begin{tabular}{lllll}
\hline Variable & Mean difference & $\mathrm{t}$ & Degrees of freedom & The significance level \\
\hline Mindfulness Skills & -5.40 & -2.45 & 158 & 0.01 \\
Metacognitive beliefs & -4.02 & -2.80 & 145.44 & 0.006 \\
Perceived stress & -1.37 & -1.27 & 158 & 0.20 \\
\hline
\end{tabular}

As the results in Table 4 show, there is a significant difference between two groups' scores of mindfulness skills and metacognitive beliefs variables but there are no significant differences in perceived stress scores between the two groups.

\section{Discussion and Conclusion}

The aim of the present study was to compare the control group with the group of patients with blood pressure who had mindfulness skills, metacognitive beliefs, and perceived stress. According to the obtained results, there is a difference between the two groups' mindfulness skills and mindfulness skills are significantly higher in hypertension people compared to control group members. The results are somewhat in line with the results obtained by Kelham (2005), Siegel (2010), Morone (2013) and Ljotsson (2010). If we want to justify this result we can say that patients with high blood pressure due to the chronic nature of this disease and its dangerous symptoms permanently check and examine them and consequently make themselves ready to react and response to their physical and psychological symptoms (Pickering, 2011). This kind of attention can increase and spread their knowledge and sensitivity. In other words hypertension patients' awareness of their condition greatly affects their cognitive and emotional responses to disease symptoms (Dressler, Astentus, \& Vitroy, 2013). This issue is in line with researches related to mindfulness interferences in the realm of medicine and psychology (Praissman , 2008). The Studies have shown that mindfulness as a dynamic and active cognitive structure is able to affect people's response in stressful and emotional situation. By using informed attention, mind awareness makes people ready to respond to dangerous situations (Valentine, 2010). It is worth mentioning that Ndubisi (2012) 
distinguishes between knowledge of mindfulness and mindfulness experience and believes that merely having mindfulness knowledge cannot help psychological health greatly, people need mindfulness skills and experience and it can be necessary for hypertension patients, as well. Hypertension patients had a higher amount of mindfulness. The instruments used in this study assess person's mindfulness.

Based on the findings, there is a difference between metacognitive beliefs in hypertension patients and control group members. Metacognitive beliefs in hypertension patients are significantly higher than control group members. The present findings are in line with Taylor (2007) and Michasun and Grossman's (2014) findings. To justify the obtained findings it can be said that metacognitive models expresses when a person has a problem or disease, he assesses his thoughts and emotions, or even pay attention, is sensitive and aware more than necessary (Fisher \& Wells, 2005). Also metacognitive knowledge can be inappropriate and subsequently inefficient so that normal thoughts which happen naturally are evaluated as threat and subsequently lead to extremist and inefficient monitoring (Wells, 2000). Also, a lot of research has shown that they gain high scores in anger, anxiety and stress tests (Brantly, 2011), in this regard, Rees and Van Koesveld (2008) believe that due to the great attention paid to their problems, patients with stress and affective problems have a higher metacognitive awareness although this awareness is biased and deviated. Therefore these patients pay extreme and concentrated attention, aroused by metacognitive processes, to negative self-assessing thoughts (Walles, 2000); while trying to control these processes (such as mental ruminations), a person needs to develop and concentrate awareness and attention on them (Wells \& Matthews, 2004). In fact, Instead of having rational thinking individuals tend to think irrationally when problems or disease become chronic or question life continuation (Davydov \& Stewart, 2013). On the other hand individuals think that they are not in control of themselves when they think unpleasantly or strangely or think they should free their mind from unwanted thoughts and even when they merely think (Marcantonio, Spada, \& Mohiyeddini, 2008), therefore any effort to control and eliminate them, needs to be aware of them and in turn increase metacognition in the individual. Purden and Clark (2009) believe that processes such as thought ignoring and inhibition represents an attempt to control people's minds and knowledge, they also believe that, this activity may lead to awareness increase.

Metacognitive model points out that responsible beliefs and worries about the disease are the side effects of metacognitions (Wells, 2006) therefore may be this is the reason for hypertension people meta-cognitive scores increase. In their self-regulating executive performance model, Morison and Wells (2003) believe that there is a relationship between the vulnerability to psychological malfunctions and disorder continuation with cognitive-attentional syndrome which is determined by extreme concentration on self, alertness to threat, rumination processing, activation of ineffective beliefs and self-regulating strategies and will fail while modifying and mediating adverse self-awareness. These syndromes are activated by individuals metacognitive beliefs, lead attention, and are considered as a source of cognitive event's interpretation, explanation and control. This Model predicts metacognitive beliefs and their consistency. Based on the other results of the research assumptions there is no significant difference between perceived stress in hypertension people and control group members. It can be because the intensity of perceived stress shows the individual's belief about the amount of stress seriousness. When a person is suffering from a serious problem or one of the family members suffers a chronic disease, his presence results in a change in family's systematic dynamism and causes stress and tension increase in family members (Knox, 2008), Given that control group were family members of patients with blood pressure, so they are also affected by pressure and stress of the disease. On the other hand, given that hypertension is a chronic disorder and patients need to meet their needs by depending on the surrounding people (Brantley, 2011), this situation could affect the mental health of the individuals and their family members especially when appropriate ways to face the stress are not used. Hereditary common ground is another reason for the lack of significant difference between the amount of perceived stress of hypertension people and control group members. The limitations of this study include small sample size, limited number of samples, and lack of disease record control.

Factors such as their economic-social status, religion, personal characteristics, and general health and the amount and type of patients' drugs use, so it is recommended to consider these restrictions in future research and investigate the relationship between other characteristics of these patients and control group members such as life satisfaction, life quality and depression with control group.

\section{Competing Interests Statement}

The authors declare that there is no conflict of interests regarding the publication of this paper.

\section{References}

Baer, R., Smith, G., \& Allen, K. (2004). Assessment of mindfulness by self-report: The Kentucky inventory of 
mindfulness skills. Assessment Journal, 11(2), 191-206. http://dx.doi.org/10.1177/1073191104268029

Bamber, R. (2012). CBT for occupational stress in health professionals: Introducing a schema-focused approach. New York: Routledge.

Brantley, P. (2011). Stress, anger, and hostility in coronary heart disease. In: A. V. Nikcevic, A. R. Kuczmperczyk, \& M. Bruch (Eds), Formulation and treatment in clinical health psychology (pp. 109-122). New York: Routledge.

Britton, B., Shahar, B., Szepsenwol, O. \& Jacobs, J. (2012). Mindfulness-based cognitive therapy improves emotional reactivity to social stress: Results from a randomized controlled trial. Journal of Behavior Therapy, 43, 365-380. http://dx.doi.org/10.1016/j.beth.2011.08.006

Cartwright, S., \& Panchal, S. (2011). The stressful effects of mergers and acquisitions. Reading, London: Whurr.

Cohen, S., Kamarck, A. (1983). Global measure of perceived stress. Journal of Health and Social Behavior, 34, 385-396. http://dx.doi.org/10.2307/2136404

Davydov, M., \& Stewart R. (2013). Depressed mood and blood pressure: The moderating effect of situation-specific arousal levels. International Journal of Psychophysiology; 85(2), 212-23. http://dx.doi.org/10.1016/j.jpsycho.2012.04.011

Dimattw, R. (2004). The psychology of health illness and Medical care, Individual perspective. Callifornia: Brooks/Cole publishing company.

Dressler, W., Stantos, J., \& Viteri, E. (2013). Blood pressure, ethnicity, and psycho social resources. Journal Psychosomatic medicine, 15, 315-323.

Ely, D., \& Mostardi, R. (2005). The effects of recent life events stress, Life assets and tempermant pattern on cardiovascular risk factors for Akorn city police officers. Journal of human stress. 17, 155-162.

Fisher, P., \& Wells, A. (2005). Experimental modification of beliefs in obsessive - compulsive disorder: a test of the metacognitive model. Journal of Behavior Research and therapy, 43(6), 821-829. http://dx.doi.org/10.1016/j.brat.2004.09.002

Fisher, P. (2012), Stress, coping and life good. Journal of personality and social psychology, 15, 325-335.

Fox, S., \& Spector, E. (2006). The many roles of control in a stressor- emotion theory of counterproductive work behavior. In Pamela L. Perrewe, L., \& Ganster, D. C. (Eds.), Research in occupational stress and well-being. Oxford: Elsevier.

Kelham, L (2005). Self-monitoring of blood pressure athome. British Medical Journal, 330, 148. http://dx.doi.org/10.1136/bmj.330.7483.148-a

Knox S.(2008). Hostility, social support and coronary heart disease. American Journal of Cardiology, 82(10), 922-60.

Lazarus, S. (1999). Stress and emotion: A new synthesis. New York: Springer.

Ljotsson, B. (2010). Internet- delivered exposure and mindfulness based therapy for irritable bowel syndrome- A randomized controlled trial. Behavior research and Therapy, 48, 531-539.

Lobban, F., Haddock, E., \& Einderman, P. (2009).The role metacopinitive beliefs auditory hallucination. Journal Personality and Individual Differences, 32(6), 1351-1363.

Marcantonio, M., Spada, M., Mohiyeddini, C. (2008). Measuring metacognitions associated with emotional distress: Factor structure and predictive validity of the meta cognitions questionnaire 30. Personality and Individual Differences, 45, 238-242. http://dx.doi.org/10.1016/j.paid.2008.04.005

Michalsen, A., Grossman, P. (2014). Psychological and Quality of- Life Outcomes from a Comprehensive Stress Reduction and Lifestyle Program in Patients with Coronary Artery Disease: Results of a Randomized Trial. Journal PsychotherPsychosom, 74, 344-52.

Morone N (2013). I Felt Like a New Person \& "The effects of mindfulness Meditation on older adults with chronic pain: Qualitative Narrative Analysis of diary entries". Journal of pain, 9(9), 841-848. http://dx.doi.org/10.1016/j.jpain.2008.04.003

Morrison, A., \& Wells, A. (2003). A comparison of Meta cognitions in patients with hallucinations, Delusions, panic disorder, and no patient controls. Behavior Research and therapy, 41, 251-256. http://dx.doi.org/10.1016/S0005-7967(02)00095-5 
Ndubisi, N.O. (2012). Mindfulness, reliability, pre-emptive conflict handling, customer orientation and outcomes in Malaysia's healthcare sector. Journal of Business Research, 65, 537-543. http://dx.doi.org/10.1016/j.jbusres.2011.02.019

Pickering, G (2011). Why are we doing so badly with the control of hypertension? Poor compliance is only part of the story. Journal clinical hypertens, 3(3), 179-182. http://dx.doi.org/10.1111/j.1524-6175.2001.00465.x

Praissman, H. (2008). Mindfulness-based stress reduction: A literature review and clinician's guide. Journal of the American Academy of Nurse Practitioners, 20, 212-216. http://dx.doi.org/10.1111/j.1745-7599.2008.00306.x

Purdon, C., \& Clark, A. (2009). Metacognition and Obsessions. Journal Clinical Psychotherapy, 6, 102-110. http://dx.doi.org/10.1002/(SICI)1099-0879(199905)6:2<102::AID-CPP191>3.0.CO;2-5

Rabi, M. (2011). Canadian hypertension education program recommendations for the management of hypertension: blood pressure measurement, diagnosis, assessment of risk, and therapy. Canadian Journal of Cardiology, 27, 415-33. http://dx.doi.org/10.1016/j.cjca.2011.03.015

Rees, S., \& Van Koesveld, E. (2008). An open trial of group metacognitive therapy for obsessive- compulsive disorder. Journal of Behavioral Therapy Experimental Psychiatry, 39(4), 451-8. http://dx.doi.org/10.1016/j.jbtep.2007.11.004

Roseman, J., \& Smith, A. (2001). Appraisal theory: Overview, assumptions,varieties, controver. In K.R. Scherer, A. Schorr, \& T. Johnstone (Eds.), Appraisal processes in emotion: Theory, methods, research. New York: Oxford University Press.

Rosenstock, M. (2008). The health belief model: Explaining health behaviour through expectancies. In K. Glanz, M. Lewis \& K. Rimer (Eds.). Health behaviour\& education: theory, research, \& practice (pp. 39-62). San Francisko, CA: Jossey-Bass.

Sheeran, P., \& Abraham, C. (2005). The health belief model. In M. Conner, \& P. Norman (Eds.), Predicting health behavior. Buckingham: Open University Press.

Shonin, E., Van Gordon, W., Slade, K., \& Griffiths, M. D. (2013). Mindfulness and other Buddhist-derived interventions in correctional settings: A systematic review. Aggression and Violent Behavior, In press. http://dx.doi.org/10.1016/j.avb.2013.01.002

Siegel, D. (2010). The mindfulness Solution (every day practices for everyday problems). New York: Guilford.

Taylor, S. (2007). Robust dimensions of anxiety sensitivity: Development and initial validation of the anxiety sensitivity index3. Journal of Psychological Assessment, 19(2), 176-188. http://dx.doi.org/10.1037/1040-3590.19.2.176

Teasdale, D., Segal, V., \& Williams M. (2003). Mindfulness training and problem formulation. Journal Clinical Psychology: Science and Practice, 10(2), 157-160. http://dx.doi.org/10.1093/clipsy.bpg017

Valentine, S., Godkin, L., \& Varca, Ph. L. (2010). Role conflict, mindfulness, and organizational ethics in an education-based healthcare institution. Journal of Business Ethics, 94, 455-469. http://dx.doi.org/10.1007/s10551-009-0276-9

Wells, A. (2000). Emotional disorders and metacognition: Innovative cognitive therapy. Chichester, UK: John Wiley \& Sons, Ltd.

Wells, A. (2006). Detached mindfulness in cognitive therapy: A metacognitive analysis and ten techniques. Journal of Rational- Emotional \& Cognitive- Behavioral Therapy, 23(4), 337-355. http://dx.doi.org/10.1007/s10942-005-0018-6

Wells, A., \& Mathews, G. (2004). Attention and emotion: A clinical perspective. Hove: Erlbum.

\section{Copyrights}

Copyright for this article is retained by the author(s), with first publication rights granted to the journal.

This is an open-access article distributed under the terms and conditions of the Creative Commons Attribution license (http...creativecommons.org.licenses.by.3.0.). 